\title{
FIXATION OF ADULT EXRTA -ARTICULAR DISTAL THIRD DIAPHYSEAL FRACTURE OF HUMERUS-A PROSPECTIVE STUDY
}

Ahmed Parvez, Singh Amit, Gupta Alok, Singh Prashant Pratap, Kumar Dinesh, Ameer Faisal, Sharma Gajendra.

1. Professor, Department of Orthopaedics, L.L.R.M. Medical College, Meerut, Uttarpradesh.

2. Junior Resident, Department of Orthopaedics, L.L.R.M.Medical College, Meerut, Uttarpradesh.

3. Junior Resident, Department of Orthopaedics, L.L.R.M.Medical College, Meerut, Uttarpradesh.

4. Junior Resident, Department of Orthopaedics, L.L.R.M.Medical College, Meerut, Uttarpradesh.

5. Assistant Professor, Department of Orthopaedics, L.L.R.M.Medical College, Meerut, Uttarpradesh.

6. Assistant Professor, Department of Plastic Surgery, L.L.R.M.Medical College, Meerut, Uttarpradesh.

7. Junior Resident, Department of Orthopaedics, L.L.R.M.Medical College, Meerut,, Uttarpradesh.

\section{CORRESPONDING AUTHOR:}

Dr. Alok Kumar, Junior Resident, Dept. of Orthopaedics, L.L.R.M. Medical College, Meerut, Uttarpradesh, India.

E-mail: drahmedparvez@yahoo.com

ABSTRACT: Distal humerus fracture in adult is very difficult to treat. It is very difficult to achieve alignment, anatomical reduction, rigid fixation, immediate mobilization and fracture union in such patient MATERIAL AND METHOD-We operate 41 patient of close extra articular fracture of distal third of humerus, using posterior approach. 10 cases were fixed with single locking plate, 6 cases by single distal multiple hole plate, 12 cases by two reconstruction plate, 6 cases by simple $\mathrm{T}$ plate,7cases by oblique metaphyseal locking plate. RESULT- Double plating with reconstruction plates provide a more rigid fixation than a single-locked plate. CONCLUSION- Fixation of extra articular distal humerus, diaphyseal fracture in adult are better with double plating than single plating, which provide more rigid fixation with early mobilization and higher mayo elbow score.

INTRODUCTION: Fractures of distal humerus are rare injuries in adults (1). Distal humeral fractures make it difficult to use upper limb for activities of daily living such as eating, wearing clothes, maintaining body hygiene etc. To use elbow effectively, stable reduction and fixation of these fractures is necessary. Fractures of the distal humerus remain a challenging problem despite advances in technique and implants. Joint function often is compromised because of stiffness, pain, and weakness. Rarely is a "normal" elbow the outcome after these fractures, but outcomes have been improved with advances in implant technology, surgical approaches, and rehabilitation protocols.

These fractures are difficult to manage because of poor bone quality in distal humerus. The appropriate treatment of extra-articular distal humerus fractures is controversial Most distal humeral fractures in adults must be treated operatively, in contrast to fractures of the proximal humerus or humeral shaft. Nonoperative treatment with the "bag of bones" technique may be reasonable in an elderly patient with significant medical comorbidities. When operative fixation is indicated for humeral shaft fractures, plate osteosynthesis is the gold standard to which other 


\section{ORIGINAL ARTICLE}

methods must be compared 5 . In distal humeral shaft fractures especially fractures at metaphyseal junction, this becomes problematic because plates of adequate length can impinge on the olecranon fossa.

We conducted this study to evaluate the clinical and functional outcomes in patients treated by different internal fixation methods for extra-articular fractures of distal third of humerus and to know the relationship between functional outcome and time(after surgery) in patients of our institution.

MATERIALS AND METHODS: Between July 2008 and December 2012, 41 patients with close extraarticular fracture of distal third of humerus, operated in our institution were included in the study. The study was a prospective study carried out on the patients with fracture distal third humerus, attending the outdoor and the emergency services of the Department of Orthopedics in our institution. The inclusion criteria were; the patients with eighteen years and above age group presented with fracture distal third humerus, patients with mature skeleton, patients who did not have other associated bony pathology in ipsilateral limb and the patients who gave their consent to undergo the procedure. The exclusion criteria were patients with fracture distal third humerus with compound injury or intraarticular involvement. Pathological fracture with infective or metabolic bone diseases etiology. Patient with co-morbid condition which preventing surgical intervention or making patients non- compliant for post operative physiotherapy and follow up, patients with local tissue condition making the surgery inadvisable. All the patients were subjected to clinical examination. Radiographic evaluation of the affected side was done at the time of allotment of study group with the anterior-posterior and lateral views. The radiographs were assessed in terms of involvement of medial and lateral column and intra articular extension. All patients were administered general anesthesia. Our standard practice was to give preoperative prophylactic intravenous antibiotic and usage of tourniquet and unipolar/bipolar diathermy for homeostasis.

They were surgically treated by posterior approach with or without olecranon osteotomy with exploration of nerves.

Forty one cases (29 dominant hand cases, 19 nondominant hand cases) of fracture were performed by a senior consultant between July 2008 and December 2012. Of the patients operated, twelve patients were fixed with two reconstruction locking plates, ten with single locking plate, seven patients with oblique metaphyseal locking plate, six patients with single distal multiple hole plate and six patients with simple T plate. In Intra-operative period, alignment of both column and rotation of distal part was manually checked. If there was any gap that was filled by autologous cortico-cancellus bone graft taken from iliac crest.

In post operative period, standard rehabilitation program started at 3rd post operative day with passive movement of elbow and shoulder. Physiotherapy with flexion-extension, supinationpronation movements at elbow joint and range of motion exercises at shoulder joint done.

Patient related outcomes and clinical evaluations were made by an independent observer. Data obtained from personal interviews and clinical examination was recorded systematically in a Performa. The Mayo elbow score was used to rate elbow function and to determine satisfaction level of each patient. They are intended to provide a score of 0 to 100, where a higher score implies a better outcome. Score is completed by clinicians. The arms were assessed clinically in which the 


\section{ORIGINAL ARTICLE}

main variables examined were pain relief, instability, range of motion and functional improvement. Radiological assessment was by antero-posterior and lateral views of the operated arm.

RESULT: A total of 41 patients involved were included in the study between July 2008 and December 2012. The primary pathology caused by trauma, either from fall from height or road-traffic accident. Of the 41 arms that were recruited, $61 \%$ or 25 were male and $39 \%$ or 16 arms were female. The mean age of patients at the time of surgery was 48 years (range 18-82 years). The follow up period vary between 12 months to 4 years, with mean follow up was 1 year 6 months. Among the group operated by two reconstruction locking plates (12 case), stability was good. Initially at 2 month, Mayo elbow performance scores were low due to impingement of soft tissue, but it improved significantly with physiotherapy and final results were good to excellent. The mean Mayo elbow performance score at pre-op and post-op 2 month, 6month and 12 month was 18.33, 77.50, 83.75 and 89.17 respectively.

In the group operated by single locking plate, out of 10 cases 4 cases went into failure with loss of fixation and impingement at olecranon fossa occurred. The mean Mayo elbow performance score at pre-op and post-op 2 month, 6month and 12 month was 10.0, 64.00, 68.50 and 70.00 respectively.

In the group operated using oblique metaphyseal locking plate (7 cases), there was no failure but stability of medial pillar was less and Mayo elbow performance scores were comparatively low. The mean Mayo elbow performance score at pre-op and post-op 2 month, 6month and 12 month was $14.29,70.71,75.71$ and 77.14 respectively.

Fixation and Mayo elbow performance scores were very good in the group operated by single distal multiple hole plate but it was very difficult to use this plate in the patients having more distally located metaphyseal fracture. The mean Mayo elbow performance score at pre-op and postop 2 month, 6month and 12 month was 18.33, 85.00, 89.17 and 90.83 respectively.

Out of 6 patients, 3 patients went into failure among the group operated using simple T plate. The mean Mayo elbow performance score at pre-op and post-op 2 month, 6month and 12 month was $9.17,58.33,59.17$ and 60.83 respectively.

In this prospective study we have preoperative Mayo scores to compare with the final Mayo scores of same group and among different operative groups. All finding were statistically tested and significant.(see table 1 and 2)

Per operative complication was noted in four cases. This was deficient medial and lateral column (had to be built up with bone graft).In post operative period two case were infected, which were treated by debridement and antibiotic treatment. In fallow up period seven case were failed which were revised either by two reconstruction plates or by single distal multiple hole plates with bone graft. 


\section{ORIGINAL ARTICLE}

TABLE - 1: Comparison of Mayo Scores at 2 Months (Unpaired t-test)

\begin{tabular}{|c|c|c|c|c|c|c|}
\hline & Pair & Mean & $\mathrm{N}$ & $\begin{array}{l}\text { Standard } \\
\text { deviation }\end{array}$ & $\begin{array}{l}\text { Standard error } \\
\text { of mean }\end{array}$ & $\begin{array}{l}\mathrm{P} \quad \text { value / } \\
\text { significance }\end{array}$ \\
\hline \multirow[t]{2}{*}{$\begin{array}{l}\text { Pair } \\
1\end{array}$} & $\begin{array}{l}\text { Reconstruction locking } \\
\text { plate }\end{array}$ & 77.50 & 12 & 5.44 & 1.57 & \multirow{2}{*}{$\begin{array}{l}0.0356 \\
\text { statistically } \\
\text { significant }\end{array}$} \\
\hline & Single locking plate & 64.00 & 10 & 19.97 & 6.32 & \\
\hline \multirow[t]{2}{*}{$\begin{array}{l}\text { Pair } \\
2\end{array}$} & $\begin{array}{l}\text { Reconstruction locking } \\
\text { plate }\end{array}$ & 77.50 & 12 & 5.44 & 1.57 & \multirow{2}{*}{$\begin{array}{l}0.0276 \\
\text { statistically } \\
\text { significant }\end{array}$} \\
\hline & $\begin{array}{l}\text { oblique metaphyseal } \\
\text { locking plate }\end{array}$ & 70.71 & 7 & 6,73 & 2.54 & \\
\hline \multirow[t]{2}{*}{$\begin{array}{l}\text { Pair } \\
3\end{array}$} & $\begin{array}{l}\text { Reconstruction locking } \\
\text { plate }\end{array}$ & 77.50 & 12 & 5.44 & 1.57 & \multirow{2}{*}{$\begin{array}{l}0.0102 \\
\text { statistically } \\
\text { significant }\end{array}$} \\
\hline & distal multiple hole plate & 85.00 & 6 & 4.47 & 1.83 & \\
\hline \multirow[t]{2}{*}{$\begin{array}{l}\text { Pair } \\
4\end{array}$} & $\begin{array}{l}\text { Reconstruction locking } \\
\text { plate }\end{array}$ & 77.50 & 12 & 5.44 & 1.57 & \multirow{2}{*}{$\begin{array}{l}0.0169 \\
\text { statistically } \\
\text { significant }\end{array}$} \\
\hline & Simple T-plate & 58.33 & 6 & 24.43 & 9.97 & \\
\hline
\end{tabular}

TABLE - 2: Comparison of Mayo Scores at 12 Months (Unpaired t-test)

\begin{tabular}{|c|c|c|c|c|c|c|}
\hline & Pair & Mean & $\mathrm{N}$ & $\begin{array}{l}\text { Standard } \\
\text { deviation }\end{array}$ & $\begin{array}{l}\text { Standard error of } \\
\text { mean }\end{array}$ & $\begin{array}{l}\mathrm{P} \quad \text { value / } \\
\text { significance }\end{array}$ \\
\hline \multirow[t]{2}{*}{$\begin{array}{l}\text { Pair } \\
1\end{array}$} & $\begin{array}{l}\text { Reconstruction locking } \\
\text { plate }\end{array}$ & 89.17 & 12 & 4.17 & 1.20 & \multirow[t]{2}{*}{$\begin{array}{l}0.0099 \\
\text { significant }\end{array}$} \\
\hline & Single locking plate & 70 & 10 & 22.97 & 7.26 & \\
\hline \multirow[t]{2}{*}{$\begin{array}{l}\text { Pair } \\
2\end{array}$} & $\begin{array}{l}\text { Reconstruction locking } \\
\text { plate }\end{array}$ & 89.17 & 12 & 4.17 & 1.20 & \multirow[t]{2}{*}{$\begin{array}{l}0.0001 \\
\text { significant }\end{array}$} \\
\hline & $\begin{array}{l}\text { oblique metaphyseal } \\
\text { locking plate }\end{array}$ & 77.14 & 7 & 6.36 & 2.40 & \\
\hline \multirow[t]{2}{*}{$\begin{array}{l}\text { Pair } \\
3\end{array}$} & $\begin{array}{l}\text { Reconstruction locking } \\
\text { plate }\end{array}$ & 89.17 & 12 & 4.17 & 1.20 & \multirow[t]{2}{*}{$\begin{array}{l}0.4226 \\
\text { significant }\end{array}$} \\
\hline & distal multiple hole plate & 90.83 & 6 & 3.76 & 1.54 & \\
\hline \multirow[t]{2}{*}{$\begin{array}{l}\text { Pair } \\
4\end{array}$} & $\begin{array}{l}\text { Reconstruction locking } \\
\text { plate }\end{array}$ & 89.17 & 12 & 4.17 & 1.20 & \multirow[t]{2}{*}{$\begin{array}{l}0.0021 \\
\text { significant }\end{array}$} \\
\hline & Simple T-plate & 60.83 & 6 & 26.91 & 10.99 & \\
\hline
\end{tabular}

DISCUSSION: Plate osteosynthesis remains the "gold standard" of fixation for humeral shaft fractures. Plating can be used for fractures with proximal and distal extension and for open fractures. It provides enough stability to allow early upper extremity weight bearing in polytrauma patients and produces minimal shoulder or elbow morbidity. Numerous reports in the literature cite high union rates, low complication rates, and rapid return to function after plate fixation of humeral shaft fractures. A good technique requires careful preoperative planning, adequate 


\section{ORIGINAL ARTICLE}

exposure of the joint and fracture, biomechanically sound internal fixation, and protection of neurovascular structures. Flexibility on the part of the surgeon and the availability of a wide range of plates and screws are necessary.

A variety of approaches have been described for reduction and fixation of distal humeral fractures. Most commonly, a posterior approach with an olecranon osteotomy has been used, but concerns about healing and symptomatic implants have led to more frequent use of a tricepsreflecting (Bryan-Morrey) or triceps-reflecting anconeus pedicle approach, as advocated by Bryan and Morrey and O'Driscoll, or a triceps-splitting approach, as advocated by McKee et al. (2). The best fracture exposure is provided by an olecranon osteotomy approach. The biomechanically soundest technique appears to be a chevron type osteotomy through the non-articular portion of the olecranon, predrilled and fixed with inter-fragmentary screw fixation augmented by a tension band wire. As more familiarity is gained with fracture patterns and reduction techniques, a tricepsreflecting or triceps-splitting approach may be selected to reduce complications. With all posterior approaches, the ulnar nerve must be carefully dissected without excessive stripping and usually is transposed anterior to the medial epicondyle at the end of the procedure.

The standard plating technique calls for plates to be placed at orthogonal angles (90-90 plating). Studies by Self et al. and Schemitsch et al. showed that direct medial and lateral plating is biomechanically sound $(3,4)$.Newer plates that are pre-contoured or $3.5-\mathrm{mm}$ compression plates are preferable to one-third tubular and $3.5-\mathrm{mm}$ reconstruction plates because of fatigue failure in the latter group in fractures with metaphyseal comminution. For low-type fractures, additional mini fragment plates may provide added fixation .Comminuted fractures may require a bridge plating technique. Anatomical reduction of each fracture fragment is unnecessary. Attaining correct alignment, rotation, and length without disrupting the soft-tissue attachments to the comminuted fragments often leads to successful healing.

Fortunately, even in the elderly, the cortical bone of the medial and lateral columns usually provides good purchase for bone screws. In a biomechanical study of internal fixation of the distal humerus, Helfet and Hotchkiss (5) found that double-plate construction with the two plates at right angles, a medial plate on the medial column and a posterior plate on the lateral column, provided the strongest fixation regardless of whether the plate was a one-third tubular or a $3.5 \mathrm{~mm}$ reconstruction plate. Schemitsch et al. (4) looked at plates of two designs placed in five different configurations. They found that when cortical contact was present, dual plates placed medially and laterally whether at $90 \hat{\mathrm{A}}^{\circ}$ to each other or in the same plane provided equivalent rigidity. When a cortical gap was present, however, they found that the combination of an anatomically designed lateral buttress Jplate and a medial reconstruction plate gave the greatest rigidity. Reestablishment of good bone contact throughout the construct, using tricortical bone graft from the iliac crest if necessary, substantially improves fixation and chances for union.

In our study patients in whom two reconstruction plates were used, obtained the best result with a mean Mayo score of 89.17. Mean Mayo score was marginally higher in distal multiple hole plate group with a value of 90.83, but its use was limited as it could not be used in patients having more distally situated metaphyseal fracture. With the use of two reconstruction plates Mayo score was initially low with a mean of 77.50 at two months, due to impingement of soft tissue but it significantly improved with physiotherapy. Two reconstruction plate construct was the most stable as compared to other plating methods and failure of fixation was zero percent in this study. 
While functional bracing has been shown to result in good outcomes in some case, some surgeons continue to favor operative fixation (6). Management is determined by fracture pattern and degree of comminution (7). Radial nerve injury, difficulty in controlling fracture alignment and elbow stiffness are some of the concerns with functional bracing (8). Jawa et al. compared functional bracing and plate fixation for treatment of extra-articular distal-third diaphyseal humeral fractures and found that operative treatment achieves more predictable alignment and potentially quicker return of function but risks iatrogenic nerve injury and infection and the need for reoperation. According to him functional bracing can be associated with skin problems and varying degrees of angular deformity, but function and range of motion are usually excellent (9).

Tejwani et al compared rigidity of fixation provided by one locking plate versus two reconstruction plates in a laboratory study on eight pairs of matched humerus fracture and concluded that double-plating provides a more rigid fixation than a single-locked plate for fixation of extra-articular comminuted distal humeral fractures (10).

In an experimental in vitro study, Korner et al. concluded that the biomechanical behavior of the osteosynthesis depends more on plate configuration than plate type. Advantages of locking compression plates are only significant if compared with dorsal plate application techniques (11). Qing Yang et al. found that an oblique MLCP applied via a posterior approach achieved an adequate internal fixation and obtained an excellent functional outcome. In our study there was no failure with Oblique Metaphyseal Locking Compression Plate but medial pillar was less stable and Mayo score was comparatively low (12).

The goal of operative treatment of humeral shaft fractures is to reestablish length, alignment, and rotation with stable fixation that allows early motion and ideally early weight bearing on the fractured extremity. If the goal of stable fixation that allows early motion is met, rehabilitation can begin within 3 days of surgery. Waddell et al. showed that disabling stiff ness develops if the elbow is immobilized for more than 3 weeks. Supervised physical therapy sessions are scheduled three times a week, along with a daily home exercise program. Dynamic flexion and extension splinting is prescribed when early motion goals are not obtained. (13)

CONCLUSION: Following surgical treatment of adult extra-articular distal humeral fractures, double plating with reconstruction plates provide a more rigid fixation than a single-locked plate. The higher stability achieved permits early mobilization. Exploration of nerves is a pre-requisite to avoid nerve injury. Initial impingement improves with physiotherapy and this obtains higher percentage of excellent results.

\section{REFERENCES:}

1. Sim FH, Morrey BF. Non-union and delayed union of distal humeral fractures. In: Morrey BF, ed. The elbow and its disorders. Second ed. Philadelphia: W.B. Saunders Co., 1993:367-82.

2. Sanchez-Sotelo J, Torchia ME, O’Driscoll SW: Principle-based internal fixation of distal humerus fractures, Tech Hand Upper Extremity Surg 5:179,2001

3. Self J, Viegas SF, Buford WL, et al: A comparison of double-plate fixation methods for complex distal humerus fractures. J Shoulder Elbow Surg 4:51, 1995. 


\section{ORIGINAL ARTICLE}

4. Schemitsch EH, Tencer AF, Henley MB. Biomechanical Evaluation of Methods of Internal Fixation of the Distal Humerus. J Orthop Trauma 1994; 8:468.

5. Helfet DL, Hotchkiss RN. Internal Fixation of the Distal Humerus: A Biomechanical Comparison of Methods. J Orthop Trauma 1990; 4:260.

6. Sarmiento A, Horowitch A, et al. Functional bracing for comminuted extra-articular fractures of the distal third of the humerus. J Bone Joint Surg Br. 1990 Mar; 72(2):283-7.

7. Ali A, Douglas $\mathrm{H}$, et al Revision surgery for nonunion after early failure of fixation of fractures of the distal humerus. J Bone Joint Surg Br. 2005 Aug; 87(8):1107-10.

8. McKee MD. Fractures of the shaft of the humerus. In Rockwood and Green's Fractures in Adults. Bucholz RW, Heckman JD, Court-Brown CM, Editors. 2006, Lippincott Williams \& Wilkins: Philadelphia. p. 1117-1159.

9. Jawa A, McCarty P, et al Extra-articular distal-third diaphyseal fractures of the humerus. A comparison of functional bracing and plate fixation. J Bone Joint Surg Am. 2006 Nov;88(11):2343-7.

10. Tejwani NC, Murthy A, et al. Fixation of extra-articular distal humerus fractures using one locking plate versus two reconstruction plates: a laboratory study. J Trauma. 2009 Mar; 66(3):795-9.

11. Korner J, Diederichs G, et al. A biomechanical evaluation of methods of distal humerus fracture fixation using locking compression plates versus conventional reconstruction plates. J Orthop Trauma. 2004 May-Jun; 18(5):286-93.

12. Quing Yang, Fang Wang, et al. Surgical treatment of adult extra-articular distal humeral diaphyseal fractures using an oblique metaphyseal locking compression plate via a posterior approach. Med Princ Pract 2012; 21:40-45.

13. Waddell JP, Hatch J, Richards R: Supracondylar fractures of the humerus-results of surgical treatment, J Trauma 28:1615, 1988 


\section{ORIGINAL ARTICLE}
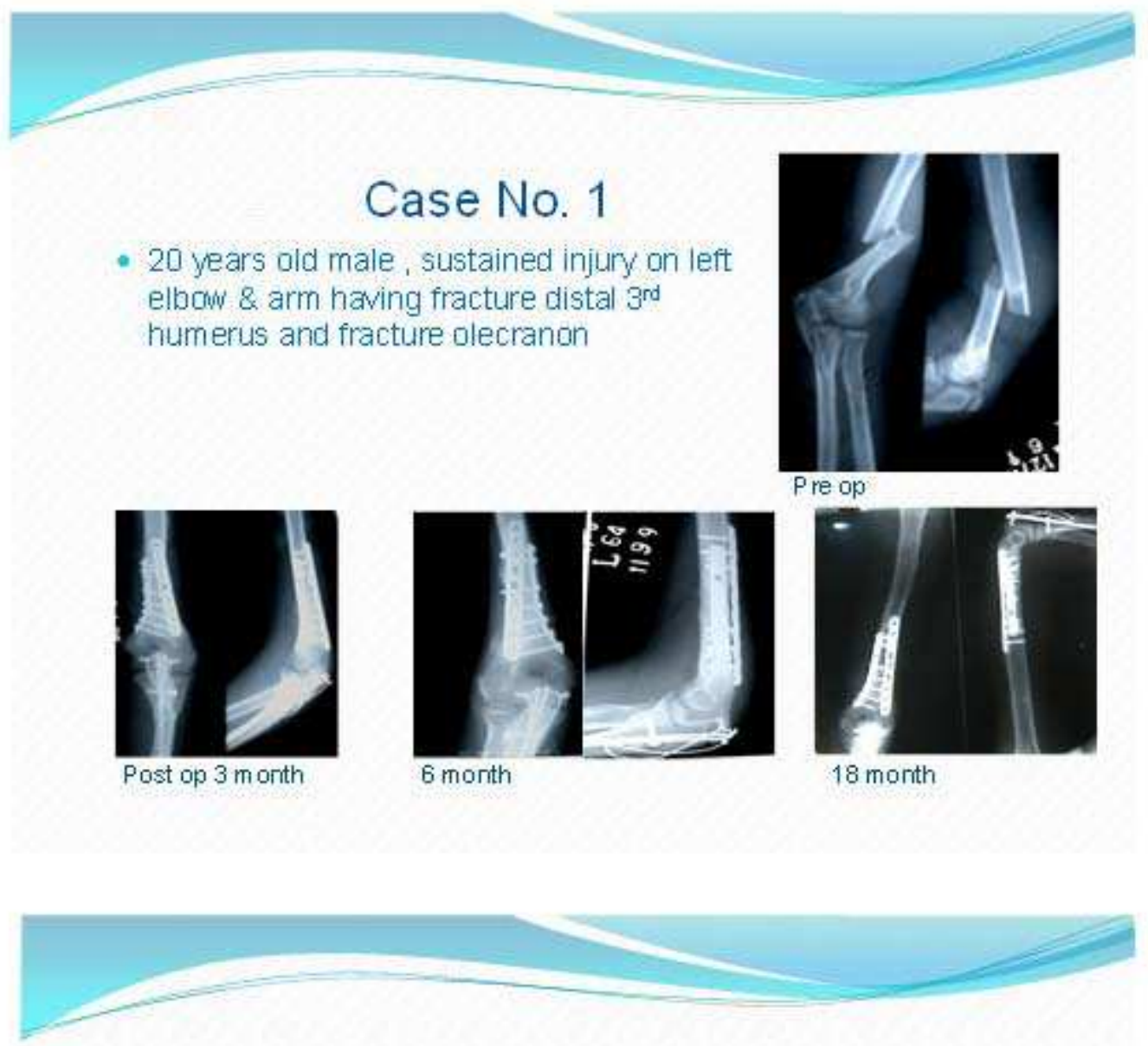

Case No. 2

- 25 years old female, with operated fracture, lower $3^{\text {rd }}$ with failed T-plate \& final fixation by two reconstruction plate.

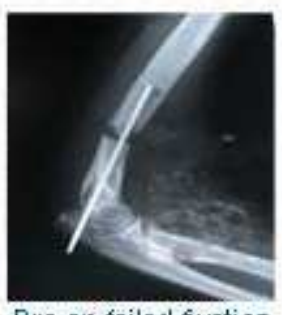

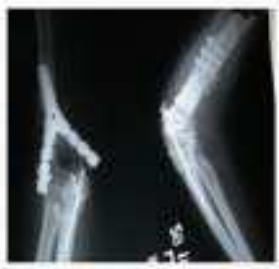

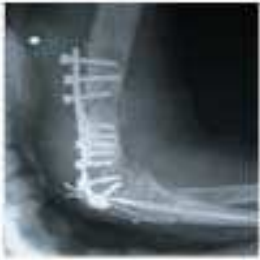

Post op fixation by T-plat ... . Failed implant

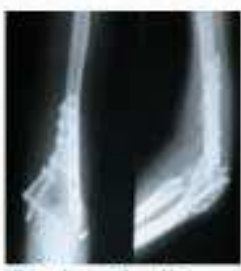

Post op fixation 3 month 


\section{ORIGINAL ARTICLE}

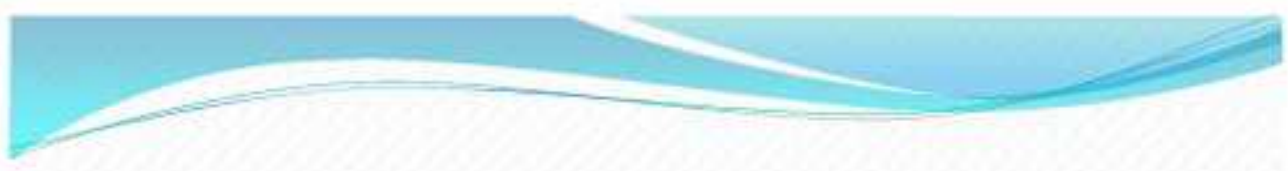

Case No. 3

- so years old female, fracture fixation by oblique metaphyseal plate.

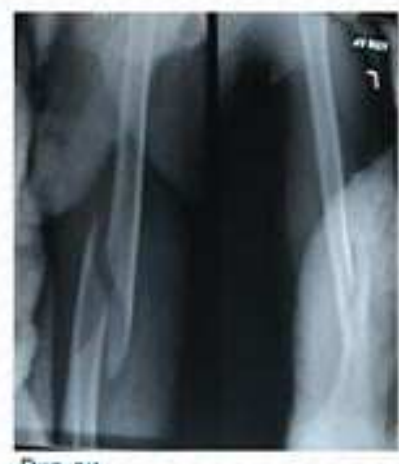

Pre op

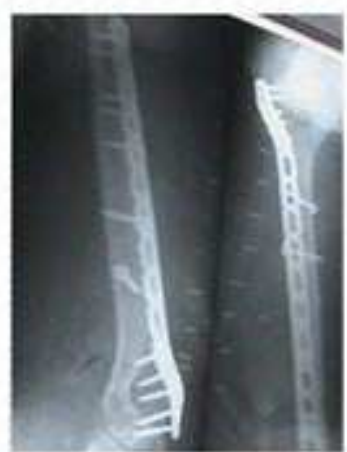

Imm odiate post op

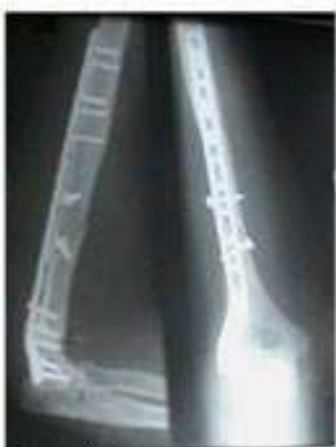

3 month

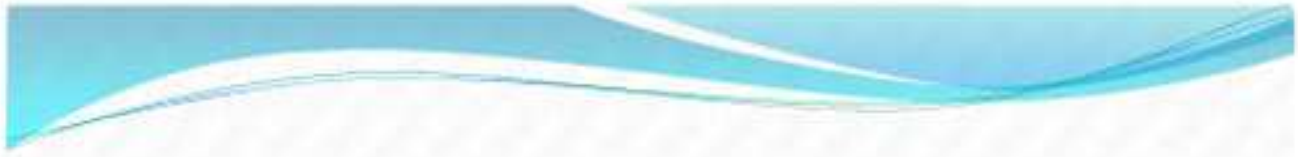

Case No. 4

- 40 years male, having fracture lower $3^{\text {rd }}$ humerus fracture fixation by two reconstruction plate withthout olecranon osteotomy

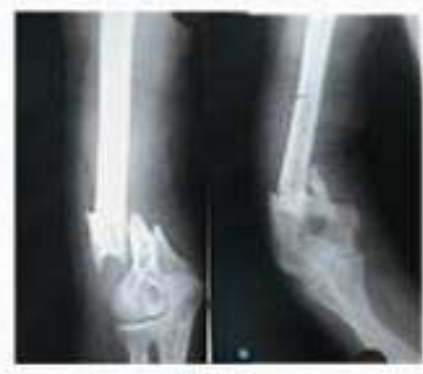

Pre op

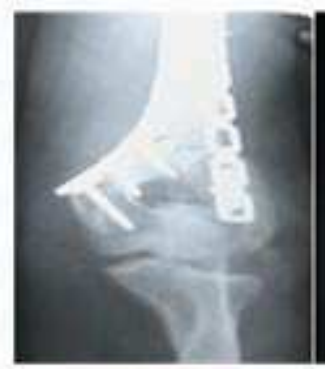

Post op 2 month

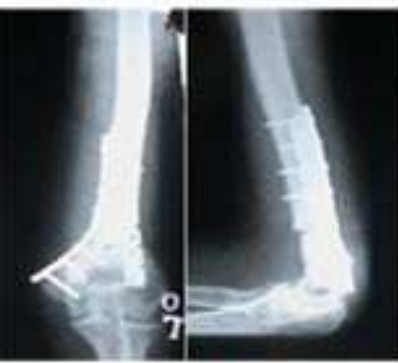

4 month 